American J. of Engineering and Applied Sciences 5 (1): 70-77, 2012

ISSN 1941-7020

(C) 2014 Kalaivani and Kamaraj, This open access article is distributed under a Creative Commons Attribution (CC-BY) 3.0 license

\title{
Enhancement of Voltage Stability by Optimal Location of Static Var Compensator Using Genetic Algorithm and Particle Swarm Optimization
}

\author{
${ }^{1}$ Kalaivani, R. and ${ }^{2}$ V. Kamaraj \\ ${ }^{1}$ Department of Electrical and Electronics Engineering, \\ Rajalakshmi Engineering College, Chennai, India \\ ${ }^{2}$ Department of Electrical and Electronics Engineering, \\ SSN College of Engineering, Chennai, India
}

\begin{abstract}
Problem statement: Voltage instability and voltage collapse have been considered as a major threat to present power system networks due to their stressed operation. It is very important to do the power system analysis with respect to voltage stability. Approach: Flexible AC Transmission System (FACTS) is an alternating current transmission system incorporating power electronic-based and other static controllers to enhance controllability and increase power transfer capability. A FACTS device in a power system improves the voltage stability, reduces the power loss and also improves the load ability of the system. Results: This study investigates the application of Particle Swarm Optimization (PSO) and Genetic Algorithm (GA) to find optimal location and rated value of Static Var Compensator (SVC) device to minimize the voltage stability index, total power loss, load voltage deviation, cost of generation and cost of FACTS devices to improve voltage stability in the power system. Optimal location and rated value of SVC device have been found in different loading scenario (115\%, 125\% and $150 \%$ of normal loading) using PSO and GA. Conclusion/Recommendations: It is observed from the results that the voltage stability margin is improved, the voltage profile of the power system is increased, load voltage deviation is reduced and real power losses also reduced by optimally locating SVC device in the power system. The proposed algorithm is verified with the IEEE 14 bus, IEEE 30 bus and IEEE 57 bus.
\end{abstract}

Key words: Voltage stability analysis, voltage collapse, SVC, UPFC, PSO, GA

\section{INTRODUCTION}

Modern power system networks are being operated under highly stressed conditions due to continuous increase in power demand. This has been imposed the threat of maintaining the required bus voltage and thus the systems have been facing voltage instability problem. Voltage stability is defined as the ability of a power system to maintain steady voltages at all the buses in the system after being subjected to a disturbance from a given initial operating condition. A system enters a state of voltage instability when a disturbance, increase in load demand, or change in system condition causes a progressive and uncontrollable decline in voltage. The main factor causing voltage instability is the inability of the power system to meet the demand for reactive power as in (Ajjarapu, 2006). Different techniques for voltage stability analysis are P-V Analysis, Q-V Analysis,
Modal Analysis and Time-Domain Analysis as in (Kundur, 1994).

FACTS have made the power systems operation more flexible and secure. They have the ability to control, in a fast and effective manner, it is also possible to control the phase angle, the voltage magnitude at chosen buses and/or line impedances of transmission system as in (Hingorani and Gyugyi, 2000) and (Mathur and Varma, 2002). FACTS controllers enhance the voltage profile and the load ability margin of power systems as in (Sode-Yome et al., 2005; Natesan and Radman, 2004). FACTS devices include Thyristor Controlled Series Compensator (TCSC), Static VAR Compensator (SVC), Thyristor Controlled Phase Angle Regulator (TCPST), Static Compensator (STATCOM), Unified Power Flow Controller (UPFC). SVC is used for voltage control applications. SVC helps to maintain a bus voltage at a desired value during load variations. The SVC can be

Corresponding Author: Kalaivani, R., Department of Electrical and Electronics Engineering, Rajalakshmi Engineering College, Chennai, India 
made to generate or absorb reactive power by adjusting the firing angle. FACTS devices can be modeled and used for power flow analysis as in (Gotham and Heydt, 1998; Acha, 2004).

There are several stochastic algorithms such as genetic algorithms, differential evolution, tabu search, simulated annealing, ant colony optimization and particle swarm optimization. Each of these algorithms has its own advantages. Particle Swarm Optimization (PSO) and Genetic Algorithms (GA) are efficient and well known stochastic algorithms.

Particle Swarm Optimization (PSO) is a population based stochastic optimization technique developed by Kennedy and Eberhart (1995), inspired by social behavior of bird flocking or fish schooling. The main idea is based on the food-searching behavior of birds as in (Kennedy and Eberhart, 1995). It is observed that they take into consideration of the global level of information to determine their direction. The global and local best positions are computed at each iteration and the output is the new direction of search. Once this direction is detected, it is followed by the cluster of birds.

The optimal location of SVC can be found using PSO in order to improve the voltage stability margin, minimize load voltage deviation and reduce power loss as in (Laifa and Boudour, 2009). Simultaneous application of Particle Swarm Optimization (PSO) and Continuation Power Flow (CPF) to improve voltage profile, minimize power system total losses and maximize system liability with respect to the size of STATCOM can be made as in (Azadani et al., 2008).

Genetic Algorithm is initially developed by John Holland, University of Michigan during 1970's; it is an iterative procedure, which maintains a constant size population of candidate solutions. During each iteration step, three genetic operators such as reproduction, crossover and mutation are performed to generate new populations and the chromosomes of the new populations are evaluated via the value of the fitness. Based on these genetic operators and the evaluations, the better new populations of candidate solution are formed. If the search goal has not been achieved, again GA creates offspring strings through three operators and the process is continued until the search goal is achieved.

A genetic algorithm is used to optimize the various process parameters involved of FACTS devices in a power system. The various parameters taken into consideration are the location of the device, their type and their rated value of the devices as in (Nikoukar and Jazaeri, 2007). Multi-type FACTS devices can be placed in optimal locations to improve security margins and reduce losses in the network as in (Baghaee et al., 2008). GA can be applied to find the optimal location of SVC to increase the power transfer capability and to reduce the generation costs as in (Metwally et al., 2008).

PSO shares many similarities with evolutionary computation techniques such as Genetic Algorithms (GA). The system is initialized with a population of random solutions and searches for optima by updating generations. In PSO, the potential solutions, called particles, fly through the problem space by following the current optimum particles. Compared to the GA, the advantages of PSO are that PSO is easy to implement and there are few parameters to adjust. GA and PSO algorithms are implemented for optimal location of SVC using MATLAB software as in (Sumathi and Surekha, 2009).

This study deals with the application of PSO and GA to find optimal location and rated value of SVC device to minimize the voltage stability index, total power loss, load voltage deviation, cost of generation and cost of FACTS devices to improve voltage stability for different load scenario in the power system.

Problem formulation: In the present study, the multiobjective function is formulated to find optimal location and size of SVC device by minimizing certain objective functions subject to satisfying some network constraints. The multi-objective problem can be written mathematically as follows as in (Malakar et al., 2010).

\section{Objective functions:}

Voltage stability index: Voltage stability is an important problem of electric power system. An indicator L-index is used to evaluate voltage stability at each bus of the system. The indicator value varies between 0 (no load case) and 1 (voltage collapse) as in (Tuan et al., 1994; Kessel and Glavitsch, 1986). L index at load bus $\mathrm{j}$ can be expressed as Eq. 1:

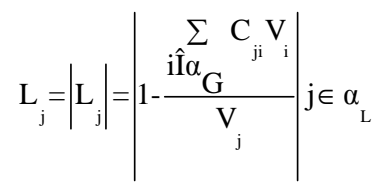

$$
\begin{aligned}
& \text { Where: } \\
& \begin{aligned}
\alpha_{\mathrm{L}} & =\text { Set of load buses } \\
\alpha_{\mathrm{G}} & =\text { Set of generator buses } \\
\mathrm{V}_{\mathrm{j}} & =\text { Complex voltage at load bus } \mathrm{j} \\
\mathrm{V}_{\mathrm{i}} & =\text { Complex voltage on generator bus } \mathrm{i} \\
\mathrm{C}_{\mathrm{ji}} & =\text { Elements of matrix C determined by: } \\
{[\mathrm{C}] } & =-\left[\mathrm{Y}_{\mathrm{LL}}\right]^{-1}\left[\mathrm{Y}_{\mathrm{LG}}\right]
\end{aligned}
\end{aligned}
$$

Matrix $\left[\mathrm{Y}_{\mathrm{LL}}\right]$ and $\left[\mathrm{Y}_{\mathrm{LG}}\right]$ are sub matrices of $\mathrm{Y}$ bus matrix Eq. 2: 
$\left[\begin{array}{c}\mathrm{I}_{\mathrm{L}} \\ \mathrm{I}_{\mathrm{G}}\end{array}\right]=\left[\begin{array}{cc}\mathrm{Y}_{\mathrm{LL}} & \mathrm{Y}_{\mathrm{LG}} \\ \mathrm{Y}_{\mathrm{GL}} & \mathrm{Y}_{\mathrm{GG}}\end{array}\right]\left[\begin{array}{c}\mathrm{V}_{\mathrm{L}} \\ \mathrm{V}_{\mathrm{G}}\end{array}\right]$

Voltage Stability Index (VSI) $=\mathrm{L}_{\max }$

where, $\mathrm{L}_{\max }=\max \left(\mathrm{L}_{\mathrm{j}}\right) \mathrm{j} \varepsilon \alpha_{\mathrm{L}}$.

The objective function considering the minimization of voltage stability index can be represented as Eq. 3:

$\mathrm{F}_{1}=\min \left(\mathrm{L}_{\max }\right)$

Fuel cost: The objective function considering the minimization of generation cost can be represented by the following quadratic Eq. 4:

$\left(F_{2}=\min \left(F\left(P_{G}\right)\right)=\sum_{i=1}^{n} a_{i} p_{i}^{2}+b_{i} P_{i}+c_{i}\right)$

where, $\mathrm{n}$ is the number of generators; $\mathrm{a}, \mathrm{b}, \mathrm{c}$ are the fuel cost coefficients of a generator unit.

Power loss: The objective of real power loss minimization is done by selecting the best combination of variables, which minimizes the total real power loss of the network simultaneously satisfying all the network constraints. Mathematically it can be expressed as Eq. 5:

$$
\begin{aligned}
& \mathrm{F}_{3}=\min \left(\mathrm{P}_{\text {loss }}\right)=\min \left(\sum_{\mathrm{i}=1}^{\mathrm{N}_{\mathrm{L}}} g_{\mathrm{i}, \mathrm{j}}\right. \\
& \left(\mathrm{V}_{\mathrm{i}}^{2}+\mathrm{V}_{\mathrm{j}}^{2}-2 \mathrm{~V}_{\mathrm{i}} \mathrm{V}_{\mathrm{j}} \cos \left(\delta_{\mathrm{i}}-\delta_{\mathrm{j}}\right)\right)
\end{aligned}
$$

Where:

$\mathrm{V}_{\mathrm{i}}=$ The voltage magnitude at bus $\mathrm{i}$

$\mathrm{g}_{\mathrm{i}, \mathrm{j}}=$ The conductance of line $\mathrm{i}-\mathrm{j}$

$\delta_{\mathrm{i}}=$ The voltage angle at bus $\mathrm{i}$

$\mathrm{N}_{\mathrm{L}}=$ The total number of transmission lines

Voltage deviation: To have a good voltage performance, the voltage deviation at each load bus must be made as small as possible. The Voltage Deviation (VD) to be minimized is as follows Eq. 6:

$$
\mathrm{F}_{4}=\min (\mathrm{VD})=\min \left(\sum_{\mathrm{i}=1}^{\mathrm{nPQ}}\left(\left|V_{i}-1\right|\right)^{2}\right)
$$

where, $\mathrm{V}_{\mathrm{i}}$ is the voltage magnitude at load bus $\mathrm{i}$.

FACTS devices cost: The objective function considering the minimization of the cost of the SVC as in (Habur and Oleary, 2004). Can be represented as Eq. 7:

$\mathrm{F}_{4}=\min \left(\mathrm{C}_{\mathrm{SVC}}\right)=\min \left(0.0003 \mathrm{~S}^{2}-0.305 \mathrm{~S}+127.38\right)$

Where:

$$
\begin{array}{ll}
\mathrm{C}_{\mathrm{SVC}} & =\text { Cost of SVC in US\$/var } \\
\mathrm{S} & =\text { Operating range of SVC in MVAR } \\
\mathrm{S} & =\left|\mathrm{Q}_{2}-\mathrm{Q}_{1}\right| \\
\mathrm{Q}_{1} & =\text { MVAR flow before placing FACTS device } \\
\mathrm{Q}_{2} & =\text { MVAR flow after placing FACTS device }
\end{array}
$$

\section{Constraints:}

Power balance constraints: The total power generated by the units must be equal to the sum of total load demand and total real power loss in the transmission lines. Hence the equality constraint Eq. 8 and 9 are:

$$
\begin{aligned}
& \mathrm{P}_{\mathrm{Gi}}-\mathrm{P}_{\mathrm{Di}}-\sum_{\mathrm{j}=1}^{\mathrm{n}}\left|\mathrm{V}_{\mathrm{i}}\right|\left|\mathrm{V}_{\mathrm{j}}\right|\left|\mathrm{Y}_{\mathrm{ji}}\right| \cos \left(\delta_{\mathrm{i}}-\delta_{\mathrm{j}}-\theta_{\mathrm{ij}}\right)=0 \\
& \mathrm{Q}_{\mathrm{Gi}}-\mathrm{Q}_{\mathrm{Di}}-\sum_{\mathrm{j}=1}^{\mathrm{n}}\left|\mathrm{V}_{\mathrm{i}}\right|\left|\mathrm{V}_{\mathrm{j}}\right|\left|\mathrm{Y}_{\mathrm{ji}}\right| \sin \left(\delta_{\mathrm{i}}-\delta_{\mathrm{j}}-\theta_{\mathrm{ij}}\right)=0
\end{aligned}
$$

Where:

$\mathrm{P}_{\mathrm{Gi}}=$ The real power generation at bus $\mathrm{i}$

$\mathrm{Q}_{\mathrm{Gi}}=$ The reactive power generation at bus $\mathrm{i}$

$\mathrm{P}_{\mathrm{Di}}=$ The real power demand at bus $\mathrm{i}$

$\mathrm{Q}_{\mathrm{Di}}=$ The reactive power demand at bus $\mathrm{i}$

$\mathrm{N}=$ The total number of buses

$\theta_{\mathrm{i}, \mathrm{j}}=$ The angle of bus admittance element $\mathrm{i}, \mathrm{j}$

$Y_{i, j}=$ The magnitude of bus admittance element $i, j$

Other constraints: The real power output of generating units, generator reactive power, voltages of all PV buses, transformer taps positions, bus voltage magnitudes of all PQ buses and power flow in the transmission line must be restricted within their respective lower and upper bounds (inequality constraints) Eq. 10-15:

$\mathrm{P}_{\mathrm{Gi}}{ }^{\mathrm{min}} \leq \mathrm{P}_{\mathrm{Gi}} \leq \mathrm{P}_{\mathrm{Gi}}{ }^{\text {max }}$ for $\mathrm{i}=1,2 \ldots \mathrm{nPV}$
$\mathrm{Q}_{\mathrm{Gi}}{ }^{{ }^{\mathrm{min}}} \leq \mathrm{Q}_{\mathrm{Gi}} \leq \mathrm{Q}_{\mathrm{Gi}}{ }^{\text {max }}$ for $\mathrm{i}=1,2 \ldots \mathrm{nPV}$

$\left|V_{i}^{\min }\right| \leq\left|V_{i}\right| \leq \mid V_{i}^{\max }$ for $\mathrm{i}=1,2 \ldots . n P V$

$\left|V_{i}^{\min }\right| \leq\left|V_{i}\right| \leq\left|V_{i}^{\max }\right|$ for $\mathrm{i}=1,2 \ldots . . \mathrm{nPQ}$

$\left|T_{i}^{\min }\right| \leq\left|T_{i}\right| \leq\left|T_{i}^{\max }\right|$ for $\mathrm{i}=1,2 \ldots . . n T$

$\mathrm{S}_{\mathrm{Li}}<\mathrm{S}_{\text {Limax }}$ for $\mathrm{i}=1,2 \ldots \mathrm{NL}$

where, $\mathrm{T}, \mathrm{S}_{\mathrm{L}}, \mathrm{nPV}, \mathrm{nPQ}, \mathrm{nT}$ and $\mathrm{NL}$ are the top position, power flow in the line, number of PV buses, PQ buses, number of tap changing transformer and the number of lines respectively.

FACTS device's constraints Eq. 16: 
$\mathrm{Q}_{\mathrm{SVC}}{ }^{{ }^{\mathrm{min}}} \leq \mathrm{Q}_{\mathrm{SVC}} \leq \mathrm{Q}_{\mathrm{SVC}}{ }^{\max }$

Where, $\mathrm{Q}_{\mathrm{SvC}}$ is the reactive power (lagging or leading) injected into the bus where the SVC is placed.

Considering all the objective functions from (3)-(7) the fitness function is expressed as Eq. 17:

Fitness function $=h_{1} F_{1}+h_{2}$

$\mathrm{F}_{2}+\mathrm{h}_{3} \mathrm{~F}_{3}+\mathrm{h}_{4} \mathrm{~F}_{4}+\mathrm{h}_{5} \mathrm{~F}_{5}$

where, $h_{1}, h_{2} h_{3}, h_{4}$ and $h_{5}$ are weighting factor of voltage stability index minimization objective function, weighting factor of fuel cost minimization objective function, weighting factor of loss minimization objective function, weighting factor of voltage deviation minimization objective function and weighting factor of FACTS cost minimization objective function respectively Eq. 18:

$\mathrm{h}_{1}+\mathrm{h}_{2}+\mathrm{h}_{3}+\mathrm{h}_{4}+\mathrm{h}_{5}=1$

The coefficients $h_{1}, h_{2}, h_{3}, h_{4}$ and $h_{5}$ are optimized by trial and error method to $0.2,0.2,0.2,0.2$ and 0.2 respectively.

Facts devices: Flexible AC Transmission Systems or FACTS introduced by the Electric Power Research Institute (EPRI) in the late 1980. FACTS devices have the ability to control the phase angle, the voltage magnitude at chosen buses and line impedances of the transmission system. In order to meet the growing power demand, utilities have an interest in better utilization of available power system capacities, existing generation and existing power transmission network, instead of building new transmission lines and expanding substations.

Mathematical model of SVC: It is a shunt-connected static var generator or absorber (Fig. 1) whose output is adjusted to exchange capacitive or inductive current so as to maintain or control specific parameters of the electrical power system (typically bus voltage). It is modeled as an ideal reactive power injection at the load ends as in (Malakar et al., 2010).

The current drawn by the SVC is Eq. 19:

$\mathrm{I}_{\mathrm{SVC}}=\mathrm{jB}_{\mathrm{SVC}} \mathrm{V}_{\mathrm{k}}$

The reactive power drawn by the SVC, which is also the reactive power injected at bus $\mathrm{k}$, is Eq. 20:

$\mathrm{Q}_{\mathrm{SVC}}=\mathrm{Q}_{\mathrm{k}}=-\mathrm{V}_{\mathrm{K}}^{2} \mathrm{~B}_{\mathrm{SVC}}$

Where:
$\mathrm{B}_{\mathrm{SVC}}=$ The susceptance of SVC

$\mathrm{V}_{\mathrm{k}}=$ The voltage at bus $\mathrm{k}$

\section{MATERIALS AND METHODS}

Particle Swarm Optimization (PSO): PSO was proposed by Kennedy and Eberhart (1995), inspired by social behavior of organisms such as bird flocking and fish schooling. PSO as an optimization tool provides a population based search procedure in which individuals called particles change their position (state) with time. In a PSO system, particles fly around in a multidimensional search space. During flight, each particle adjusts its position according to its own experience and according to the experience of a neighboring particle, making use of the best position encountered by itself and its neighbor as in (Kennedy and Eberhart, 1995).

Mathematical model of PSO: The swarm of particles initialized with a population of random candidate solutions move through the d-dimension problem space to search the new solutions. The fittest, f, can be calculated. Each particle has a position and a velocity. After every iteration the best position among the swarm so is stored Eq. 21-23:

$$
\begin{aligned}
& \mathrm{v}_{\mathrm{i}}^{\mathrm{k}+1}=\mathrm{w}_{\mathrm{i}} \mathrm{v}_{\mathrm{i}}^{\mathrm{k}}+\mathrm{c}_{1} \times \operatorname{rand}_{1} \times\left(\text { pbest }_{\mathrm{i}}-\mathrm{s}_{\mathrm{i}}^{\mathrm{k}}\right) \\
& +\mathrm{c}_{2} \times \operatorname{rand}_{2} \times\left(\text { gbest }_{\mathrm{i}}-\mathrm{s}_{\mathrm{i}}^{\mathrm{k}}\right) \\
& \mathrm{s}_{\mathrm{i}}^{\mathrm{k}+1}=\mathrm{s}_{\mathrm{i}}^{\mathrm{k}}+\mathrm{v}_{\mathrm{i}}^{\mathrm{k}+1} \\
& \mathrm{w}=\mathrm{w}_{\text {max }}-\frac{\mathrm{w}_{\text {max }}-\mathrm{w}_{\min }}{\text { iterw }_{\text {max }}} \times \text { iter }
\end{aligned}
$$

Where:

$\mathrm{V}_{\mathrm{i}}^{\mathrm{k}}=$ Velocity of $\mathrm{i}^{\text {th }}$ particle at kth iteration

$\mathrm{V}_{\mathrm{i}}^{\mathrm{k}+1}=$ Velocity of $\mathrm{i}^{\text {th }}$ particle at $(\mathrm{k}+1)^{\mathrm{th}}$ iteration

$\mathrm{S}_{\mathrm{i}}^{\mathrm{k}} \quad=$ Current position of particle $\mathrm{i}$ at $\mathrm{k}^{\text {th }}$ iteration

$\mathrm{S}_{\mathrm{i}}^{\mathrm{k}+1}=$ Current position of particle $\mathrm{i}$ at $(\mathrm{k}+1)^{\mathrm{th}}$ Iteration

$\mathrm{P}_{\text {best } \mathrm{i}}=$ Best position of $\mathrm{i}^{\text {th }}$ particle

$\mathrm{G}_{\text {best } \mathrm{i}}=$ Best position among the particles (group best)

$\mathrm{c}_{1:} \quad=$ Coefficient of the self-recognition component,

$\mathrm{c}_{2} . \quad=$ Coefficient of the social component

$\mathrm{c}_{1}+\mathrm{c}_{2}=4 \operatorname{rand}_{1}$ and $\operatorname{rand}_{2}$ are the random numbers usually chosen between $[0,1]$

$\mathrm{w}=$ Inertia weight

$\mathrm{w}_{\max }=$ Initial value of inertia weight 


$$
\begin{array}{ll}
\mathrm{W}_{\min } & =\text { Final value of inertia weight } \\
\text { iter } & =\text { Current iteration number } \\
\text { iterw }_{\max } & =\text { Maximum iteration number }
\end{array}
$$

Genetic Algorithm (GA): GA is an evolutionary computing method in the area of artificial intelligence. It is a stochastic global search and optimization method that is based on the concepts of natural genetics and the Darwinian survival-of-the-fittest code. Genetics is usually used to reach to a near global optimum solution. In each iteration of GA, a new set of string (i.e., chromosomes) with improved fitness is produced using genetic operators (i.e., selection crossover and mutation). The main components of GA Algorithm are initialized, selection, crossover, mutation and termination as in (Nikoukar and Jazaeri, 2007).

Parent selection: The better fitness values among the population are selected as the parents to produce a better generation. This fittest test is accomplished by adopting a selection scheme in which higher fitness individuals are being selected for contributing offspring in the next generation. Many selection schemes such as Roulette Wheel, Random, Rank, Tournament and Boltzmann selection schemes are available.

Reproduction: Reproduction is based on the principle of better fitness survival. It is an operator that obtains a fixed copy number of solutions according to their fitness value. If the score increases, the number of copies increases too. A score value is associated with a solution relying on its distance from the optimal solution (closer distances to the optimal solution mean higher scores).

Crossover: The objective of crossover operator is to produce new individuals that are different from their parents but inherit their parents' genetic material. A selected chromosome is divided into two parts and recombining with another selected chromosome, which has also been divided at the same crossover point. Many crossover schemes such as single point, two point, multipoint and uniform crossover are available.

Mutation: Mutation is used both to avoid premature convergence of the population (which may cause convergence to a local, rather than global, optimum) and to fine-tune the solutions. The mutation operator has defined by a random bit value change in a casing string with a low probability of such change.

\section{RESULTS}

The solutions for optimal location of SVC device to minimize the objective function for the
IEEE 14 bus, IEEE 30 bus and IEEE 57 bus systems were obtained and discussed below. The test system data used as in power system test case achieves. The location, setting of SVC device, optimal objective function value, voltage profile and total real power losses of the power system are obtained using the PSO and GA techniques. The parameters used for GA and PSO techniques are shown in Table 1. The location, setting of SVC device are also found in different load scenario. The proposed PSO and GA techniques are tested on standard IEEE 14 bus, IEEE 30 bus and IEEE 57 bus systems.

IEEE 14bus system: It contains 20 lines. The test system consists of 5 generator buses (bus no. 1,2,3,6 and 8), 9 load buses (bus no. 4,5,7,9,10,11,12,13 and 14) and 20 transmission lines. The real power load is increased by 115,125 and $150 \%$. Optimal location and rating of SVC for different load scenario for IEEE 14 Bus using GA and PSO have been shown in Table 2. Real power loss for different load scenario for IEEE 14 Bus is given Table 3 .

Comparison of voltage profile and Comparison of IEEE 14 Bus system for without SVC, with SVC at bus 13 obtained from the GA and with SVC at bus 7 obtained from PSO for normal loading condition are shown in Fig. 2.

Table 1: GA and PSO parameters

\begin{tabular}{lrlr}
\hline------ & & \\
\hline Population & 20.0 & Population & 10.0 \\
Crossover fraction & 0.8 & $\mathrm{C} 1$ & 2.5 \\
Migration fraction & 0.2 & $\mathrm{C} 2$ & 1.5 \\
Elite count & 2.0 & $\mathrm{~W}$ max & 0.9 \\
& & Wmin & 0.4 \\
\hline
\end{tabular}

Table 2: Optimal location and rating of SVC for different load scenario for IEEE 14Bus using GA and PSO

\begin{tabular}{lllll}
\hline & GA & & PSO & \\
Loading & -- & & - \\
condition & Location & Rating & Location & Rating \\
\hline Normal loading & 13 & 0.2376 & 7 & 0.2481 \\
115\% loading & 13 & 0.0082 & 7 & 0.2481 \\
125\% loading & 11 & 0.0115 & 7 & 0.2481 \\
150\%loading & 9 & -0.2499 & 7 & 0.2481 \\
\hline
\end{tabular}

Table 3: Real power loss for different load scenario for IEEE 14Bus

\begin{tabular}{llll}
\hline Loading condition & Without SVC & GA & PSO \\
\hline Normal loading & 13.593 & 13.520 & 13.554 \\
$115 \%$ loading & 18.727 & 18.521 & 18.549 \\
125\% loading & 22.961 & 22.397 & 22.390 \\
150\%loading & 37.012 & 33.699 & 33.891 \\
\hline
\end{tabular}


Am. J. Engg. \& Applied Sci., 5 (1): 70-77, 2012

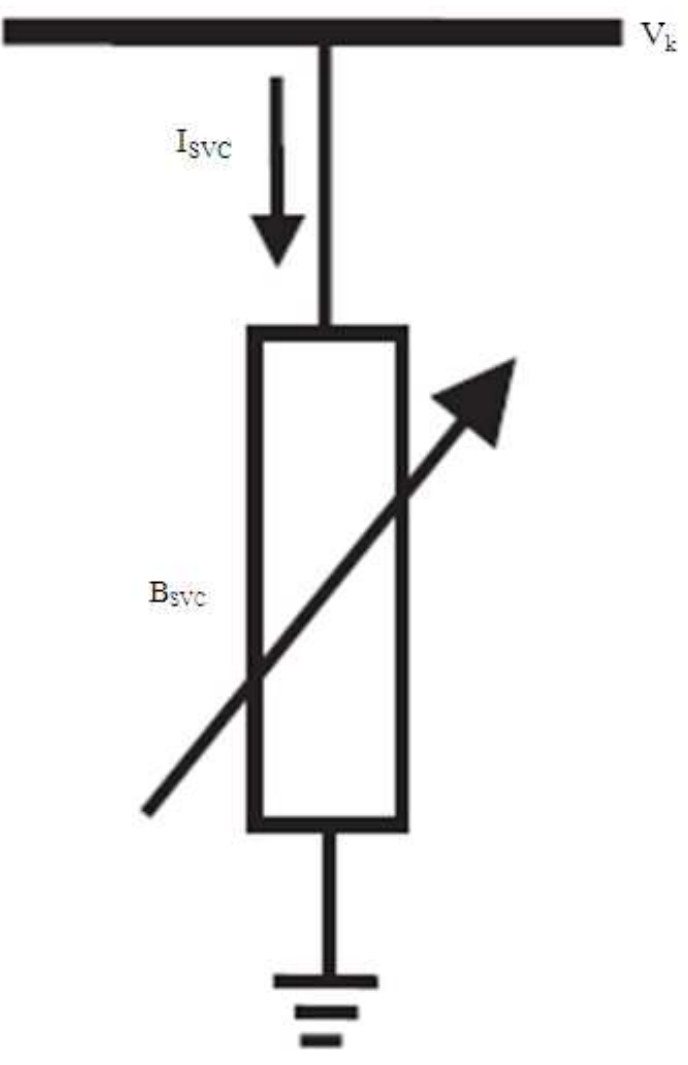

Fig. 1: Variable shunt susceptance model

Table 4: Optimal location and rating of SVC for different load scenario for IEEE 30 Bus using GA and PSO

\begin{tabular}{|c|c|c|c|c|}
\hline \multirow{2}{*}{$\begin{array}{l}\text { Loading } \\
\text { condition }\end{array}$} & \multicolumn{2}{|l|}{ GA } & \multicolumn{2}{|l|}{ PSO } \\
\hline & Location & Rating & Location & Rating \\
\hline Normal loading & 19 & 0.2335 & 17 & -0.1189 \\
\hline $115 \%$ loading & 29 & 0.0241 & 17 & -0.1189 \\
\hline $125 \%$ loading & 27 & 0.2123 & 17 & -0.1189 \\
\hline $150 \%$ loading & 24 & 0.0983 & 17 & -0.1189 \\
\hline
\end{tabular}

Table 5: Real power loss for different load scenario for IEEE 30

\begin{tabular}{llll}
\hline Loading condition & without SVC & GA & PSO \\
\hline Normal loading & 17.571 & 17.523 & 17.543 \\
$115 \%$ loading & 24.589 & 24.053 & 24.028 \\
125\% loading & 29.662 & 28.992 & 29.041 \\
$150 \%$ loading & 49.675 & 44.168 & 44.127 \\
\hline
\end{tabular}

Table 6: Optimal location and rating of SVC for different load scenario for IEEE 57 Bus using GA and PSO

\begin{tabular}{lllll}
\multicolumn{5}{c}{ Scenario for IEEE 57 Bus using GA and PSO } \\
\hline & GA & & PSO & \\
Loading & -------------- & ----------------- \\
condition & Location & Rating & Location & Rating \\
\hline Normal loading & 36 & 0.2335 & 41 & -0.0763 \\
115\% loading & 36 & 0.2335 & 41 & -0.0763 \\
125\% loading & 36 & 0.0692 & 41 & -0.0763 \\
150\%loading & 38 & 0.0086 & 41 & -0.0763 \\
\hline
\end{tabular}

Table 7: Real power loss for different load scenario for IEEE 57 Bus

\begin{tabular}{llrr}
\hline Loading Condition & without SVC & GA & \multicolumn{1}{c}{ PSO } \\
\hline Normal loading & 28.681 & 27.832 & 28.116 \\
$115 \%$ loading & 50.149 & 49.089 & 50.068 \\
$125 \%$ loading & 72.877 & 69.834 & 71.134 \\
$150 \%$ loading & 167.407 & 150.124 & 152.259 \\
\hline
\end{tabular}

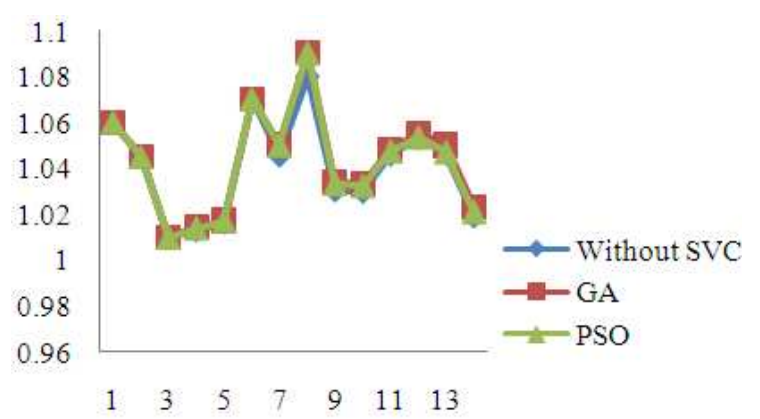

Fig. 2: Voltage profile of IEEE 14 Bus system for normal loading condition

IEEE 30 bus system: The test system consists of 6 generator buses (bus no. 1, 2, 5 ,8, 11, and 13), 24 load buses (bus no. 3, 4, 6, 7, 9, 10, 12, $14,15,16,17,18$, $19,20,21,22,23,24,25,26,27,28,29$ and 30) and 41 transmission lines. The total system demand is 283.4 MW. The real power load is increased by 115, 125 and $150 \%$. Optimal location and rating of SVC for different load scenario for IEEE 30 Bus using GA and PSO have been shown in Table 4. Real power loss for different load scenario for IEEE 30 Bus is given Table 5.

Comparison of the voltage profile of IEEE 30 Bus system for without SVC, with SVC at bus 19 obtained from the GA and with SVC at bus 17 obtained from PSO for normal loading condition are shown in Fig. 3.

IEEE 57 bus system: The test system consists of 7 generator buses (bus no. 1,2,3,6,8,9,12) 50 load buses (bus no. 4, 5, 7, 10, 11, 13, 14, 15, 16, 17, 18, 19, 20, $21,22,23,24,25,26,27,28,29,30,31,32,33,34,35$, $36,37,38,39,40,41,42,43,44,45,46,47,48,49,50$, $51,52,53,54,55,56,57)$ and 80 transmission lines. The total system demand is $1195.8 \mathrm{MW}$. The real power load is increased by 115,125 and $150 \%$. Optimal location and rating of SVC for different load scenario for IEEE 57 Bus using GA and PSO have been shown in Table 6. Real power loss for different load scenario for IEEE 57 Bus is given Table 7. Comparison of the voltage profile of IEEE 57 Bus system for without SVC, with SVC at bus 36 obtained from GA, with SVC at bus 41 obtained from PSO for normal loading condition are shown in Fig. 4. 


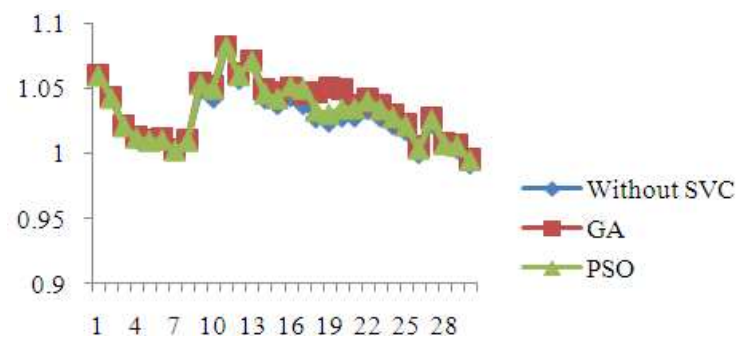

Fig. 3: Voltage profile of IEEE 30 Bus system for normal loading condition

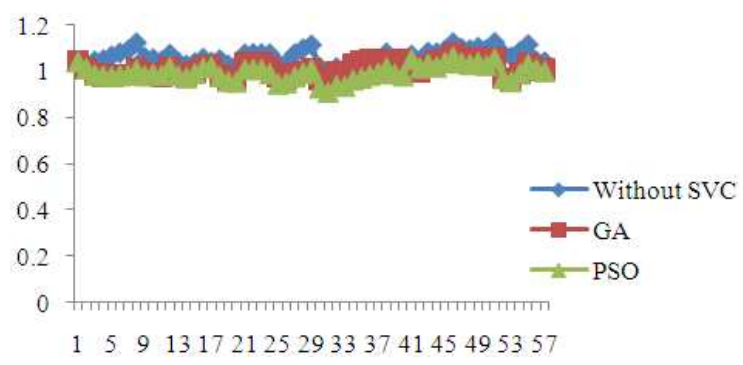

Fig. 4: Voltage profile of IEEE 57 Bus system for normal loading condition

\section{DISCUESSION}

For IEEE 14 Bus normal loading, Bus 13 is identified as the optimal location of SVC using GA and a susceptance rating of SVC is 0.2376 p.u. And the voltage profile is increased at all the buses and a real power loss is reduced by $7.3 \%$. Bus 7 is identified as the optimal location of SVC using PSO and a susceptance rating of SVC is 0.2481 p.u. And the voltage profile is increased at all the buses and a real power loss is reduced by $3.9 \%$. Voltage profile is increased at all the buses and a real power loss is reduced for a load increase to 110,125 and $150 \%$ of normal loading.

For IEEE 30 Bus, Bus 19 is identified as the optimal location of SVC using GA and a susceptance rating of SVC is 0.2335 p.u. And the voltage profile is increased at all the buses and a real power loss is reduced by $4.8 \%$. Bus 17 is identified as the optimal location of SVC using PSO and a susceptance rating of SVC is -0.1189 p.u. And the voltage profile is increased at all the buses and a real power loss is reduced by $2.8 \%$. Voltage profile is increased at all the buses and a real power loss is reduced for a load increase to 110,125 and $150 \%$ of normal loading.

For IEEE 57 Bus, optimal location of SVC using GA is Bus 36 and susceptance rating of SVC is 0.2335 p.u. And the voltage profile is increased at all the buses and a real power loss is reduced by $84.9 \%$. Bus 41 is identified as the optimal location of SVC using PSO and a susceptance rating of SVC is -0.0763 p.u. And the voltage profile is increased at all the buses and a real power loss is reduced by $56.5 \%$. Voltage profile is increased at all the buses and a real power loss is reduced for a load increase to 110,125 and $150 \%$ of normal loading.

\section{CONCLUSION}

This study made an attempt to find the optimal location and size of SVC device for decreasing voltage stability index, power loss, voltage deviation, the cost of generating unit and cost of SVC device using PSO and GA for different loading condition. Simulations were performed on IEEE 14, 30 and 57 bus systems. It is observed that for all load increase i.e., $110 \%, 125 \%$ and $150 \%$ of normal loading, the voltage stability margin is improved, the voltage profile of the power system is increased, load voltage deviation is reduced, cost of generator units and SVC is decreased and real power losses also reduced by optimally locating SVC device in the power system. GA results are better than that of PSO and conventional methods.

\section{REFERENCES}

Acha, E., 2004. Facts: Modelling and Simulation in Power Networks. 1st Edn., John Wiley and Sons, Chichester, ISBN-10: 0470852712, pp: 403.

Ajjarapu, V., 2006. Computational Techniques for Voltage Stability Assessment and Control. 1st Edn., Springer, New York, ISBN-10: 0387260803, pp: 250.

Azadani, E.N., S.H. Hosseinian and P. Hasanpor, 2008. Optimal placement of multiple STATCOM for voltage stability margin enhancement using particle swarm optimization. Elect. Eng., 90: 503-510. DOI: $10.1007 / \mathrm{s} 00202-008-0101-y$

Baghaee, H.R., M. Jannati, B. Vahidi, S.H. Hosseinian and S. Jazebi, 2008. Optimal multi-type FACTS allocation using genetic algorithm to improve power system security. Proceedings of the 12th International Middle-East Power System Conference, Mar. 12-15, IEEE Xplore Press, Aswan, $\quad$ pp: 162-166. DOI: 10.1109/MEPCON.2008.4562387

Gotham, D.J. and G.T. Heydt, 1998. Power Flow control and Power Flow Studies for Systems with FACTS devices. IEEE Trans. Power Syst., 13: 6065. DOI: $10.1109 / 59.651614$

Habur, K. and D. O'Leary, 2004. FACTS-flexible alternating current transmission systems, for cost effective and reliable transmission of electrical energy. 
Hingorani, N.G. and L. Gyugyi, 2000. Understanding FACTS: Concepts and Technology of Flexible AC Transmission Systems. 1st Edn., IEEE Press, New York, ISBN-10: 0780334558, pp: 432.

Kennedy, J. and R. Eberhart, 1995. Particle swarm optimization. Proceedings of the IEEE International Conference on Neural Networks, Nov. 27-Dec. 1, IEEE Xplore Press, Perth, WA., pp: 1942-1948. DOI: 10.1109/ICNN.1995.488968

Kessel, P. and H. Glavitsch, 1986. Estimating the voltage stability of a power system. IEEE Trans. Power Delivery, 1: 346-354. DOI: 10.1109/TPWRD.1986.4308013

Kundur, P., 1994. Power System Stability and Control. 1st Edn., Tata McGraw-Hill Education, New York, ISBN-10: 0070635153, pp: 1176.

Laifa, A. and M. Boudour, 2009. Optimal location of Svc for voltage security enhancement using MOPSO. Proceedings of the Third International Conference on Electrical Engineering, May 19-24, USTHB, Algiers, pp: 73-78.

Malakar, T., N. Sinha, S.K. Goswami and L.C. Saikia, 2010. Optimal location and size determination of facts devices by using multiobjective optimal power flow. Proceedings of the 2010 IEEE Region 10 Conference, Nov. 21-24, IEEE Xplore Press, Fukuoka, pp: 474-478. DOI: 10.1109/TENCON.2010.5686706

Mathur, R.M. and R.K. Varma, 2002. Thyristor-Based Facts Controllers for Electrical Transmission Systems. 1st Edn., IEEE Press, New York, ISBN10: 0471206431, pp: 495.
Metwally, M.M.E., A.A. El Emary, F.M. El Bendary and M.I. Mosaad, 2008. Optimal allocation of facts devices in power system using genetic algorithms. Proceedings of the 12th International Middle-East Power System Conference, Mar. 12-15, IEEE Xplore Press, Aswan, pp: 1-4. DOI: 10.1109/MEPCON.2008.4562386

Natesan, R. and G. Radman, 2004. Effects of STATCOM, SSSC and UPFC on voltage stability. Proceedings of the 36th Southeastern Symposium on System Theory, (SSST' 04), IEEE Xplore Press, pp: 546-550. DOI: 10.1109/SSST.2004.1295718

Nikoukar, J. and M. Jazaeri, 2007. Genetic algorithm applied to optimal location of FACTS devices in a power system. Proceedings of the 3rd IASME/WSEAS International Conference on Energy, Environment, Ecosystems and Sustainable Development, Jul. 24-26, Agios Nikolaos, Greece, pp: 526-531.

Sode-Yome, A., N. Mithulananthan and K.Y. Lee, 2005. Static voltage stability margin enhancement using STATCOM, TCSC and SSSC. Proceedings of the IEEE/PES Transmission and Distribution Conference and Exhibition: Asia and Pacific, Aug. 18-18, IEEE Xplore Press, Dalian, pp: 1-6. DOI: 10.1109/TDC.2005.1547141

Sumathi, S. and P. Surekha, 2009. Computational Intelligence Paradigms: Theory and Applications Using MATLAB. 1st Edn., CRC Press, Taylor and Francis, ISBN-10: 143980902X, pp: 829.

Tuan, T.Q., J. Fandino, N. Hadjsaid, J.C. Sabonnadire and $\mathrm{H}$. Vu, 1994. Emergency load shedding to avoid risks of voltage instability using indicators. IEEE Trans. Power Syst., 9: 341-351. DOI: 10.1109/59.317592 